\title{
Promoting children's pain alleviation in emergency department
}

\author{
BM Cantoni \\ From 70th Congress of the Italian Society of Pediatrics, Joint National Meeting SIP, SICuPP, SITIP \\ Palermo, Italy. 11-14 June 2014
}

\section{Background}

Pain is, by nature, a subjective experience influenced by social, psychological, and experiential factors.

Nowadays, pain relief is considered an imperative of the pediatric emergency nursing. Analgesia administration influences the entire child's medical experience and can have a lasting effect on patient and family's reaction to current and future medical cares [1].

Pain assessment represents the first step for analgesia management and it should be performed routinely by nurses in emergency department (ED) triage along with vital signs monitoring. Increasing evidence indicates that prompt pain evaluation improves the whole quality of subsequent care. Findings from studies investigating the use of scales for pain evaluation, in addition to the experience gained in clinical practice, suggest to treat all patients presenting a pain intensity major than 4 [2] (scale's range from 0 - no pain to 10 - the worst pain experienced). However, the myth that analgesic treatments would mask symptoms and delay diagnosis in some cases (i.e. children with acute abdominal disease) still frightens physicians and nurses. Therefore, pain reduction is often not considered as a primary task to be accomplished by the ED team [3].

\section{Materials and methods}

We retrospectively analyzed data regarding admission causes, pain assessment (Numeric Rate Scale, Face, Legs, Activity, Cry, Consolability scale) and management of 23677 children admitted to the pediatric ED of the " $\mathrm{Ca}$ ' Granda Ospedale Maggiore Hospital in Milan between January and December 2013.

\section{Results}

The first reason requiring medical attention was fever (37\%). Pain was the second cause (25\%). Moreover, children affected by other disease reported concomitant pain in $42 \%$ of cases.

Pain was assessed and recorded in $85 \%$ of children. A pain with an intensity major than 4 was detected in $31 \%$ of cases. Only $72 \%$ were treated with an analgesic drug. The non-treated children suffered from abdominal pain. Acetaminophen was the main drug administered (15 mg/kg/dose).

\section{Conclusions}

Our data indicate that pain is an important cause of concern for families that leads to medical consultation. However, pain assessment at triage is not performed in all patients, yet. Although several data show that analgesia does not mask signs of acute abdominal diseases, nurses still avoid the prompttreatment of abdominal pain. Although non-pharmacological interventions, such as distraction, positioning, sucrose, have been described to be useful in reducing abdominal pain [4] they are often unsatisfactory. In conclusion, we suggest that educational interventions and staff trainings should be addressed to promote children's pain alleviation at triage.

Published: 11 August 2014

\footnotetext{
References

1. Williams S, Holzhauser K, Bonney D, Burmeister E, Gilhotra Y, Oliver R, Gordon K: Improving pain management of abdominal pain in children presenting to the pediatric emergency department: A pre-post interventional study. Australas Emerg Nurs J 2012, 15:133-47.

2. Twycross A, Collins S: Nurses' Views About the Barriers and Facilitators to Effective Management of Pediatric Pain. Pain Manag Nurs 2013, 14: e164-e172.

3. Fein JA, Zempsky WT, Cravero JT, The Committee On Pediatric Emergency Medicine And Section On Anesthesiology And Pain Medicine: Relief of Pain and Anxiety in Pediatric Patients in Emergency Medical Systems Pediatrics. Pediatrics 2012, 130:e1391.
}

Correspondence: barbara.cantoni@policlinico.mi.it

SITRA Area Assistenziale della Pediatria Fondazione IRCCS Ca' Granda Ospedale Maggiore Policlinico, 20122 Milan, Italy 
4. Sarah JK, Wente RN, Richfield MN: Non pharmacologic pediatric pain management in emergency departments: a systematic review of the literature. J Emerg Nurs 2013, 39:140-50.

doi:10.1186/1824-7288-40-S1-A53

Cite this article as: Cantoni: Promoting children's pain alleviation in emergency department. Italian Journal of Pediatrics 2014 40(Suppl 1):A53.

Submit your next manuscript to BioMed Central and take full advantage of:

- Convenient online submission

- Thorough peer review

- No space constraints or color figure charges

- Immediate publication on acceptance

- Inclusion in PubMed, CAS, Scopus and Google Scholar

- Research which is freely available for redistribution

Submit your manuscript at www.biomedcentral.com/submit

() BioMed Central 